\title{
APORTES DEL "NONÁGONO SEMIÓTICO” PARA LA COMPRENSIÓN DE LA IDENTIDAD VISUAL Y SU POTENCIA SOCIAL ${ }^{1}$
}

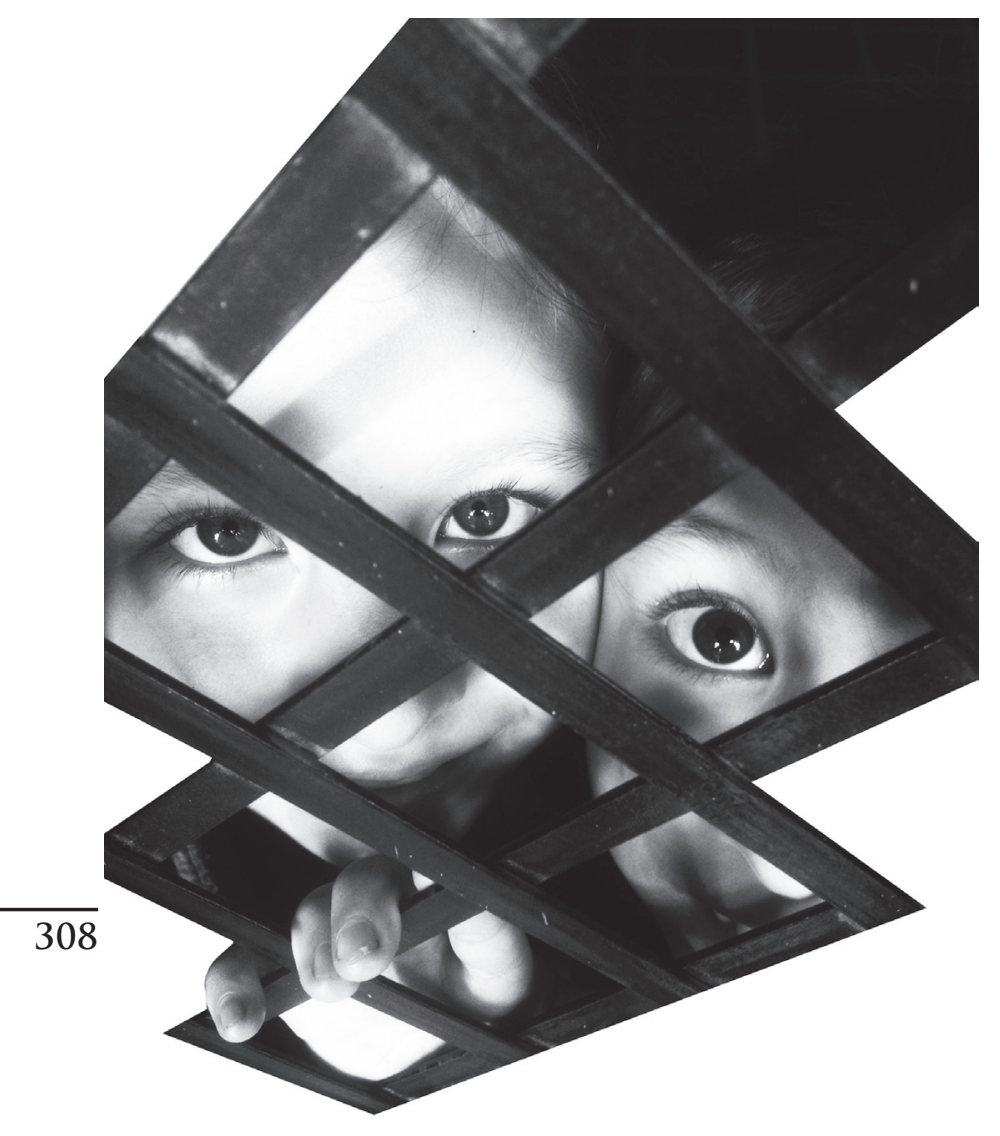

\author{
CONTRIBUTIONS OF THE \\ "SEMIOTIC NONAGON" TO \\ THE COMPREHENSION OF THE \\ VISUAL IDENTITY AND ITS \\ SOCIAL POTENTIA
}

\author{
CONTRIBUIÇÕES DO \\ "ENEÁGONO SÉMIÓTICO" \\ PARA O ENTENDIMENTO DA \\ IDENTIDADE VISUAL E O SEU \\ POTENCIAL SOCIAL
}

Por:

María Ximena Betancourt Ruiz ${ }^{2}$

Profesora

Universidad Jorge Tadeo Lozano

Bogotá, Colombia

mariax.betancourtr@utadeo.edu.co

Resumen: Este artículo ubica metodológicamente la investigación "De la identidad social a la representación visual" en un modelo operativo de orden cualitativo que parte de la semiótica. Se dibuja en principio una apropiación del modelo utilizado por Silva (2004) en la investigación "Imaginarios Urbanos en América Latina” para posteriormente complejizarlo y problematizarlo a través del nonágono semiótico, modelo propuesto por Claudio Guerri (2014) basado en la riqueza de la pragmática de Peirce. El nonágono para esta investigación resulta una herramienta fundamental para razonar, entender y comprender el objeto de estudio, pero también para precisar, a partir de este razonamiento, el proceso creativo, su resultante y su impacto.

Palabras clave: Nonágono semiótico, Identidad social, Identidad visual. 
Abstract: This article places methodologically the research work "From social identity to the visual representation," in an operational model of qualitative order based on semiotics. It outlined an appropriation of the model used by Silva (2014) in the research work "Urban Imaginaries from Latin America" and later elaborates on and brings into question through the "Semiotic Nonagon", a model proposed by Claudio Guerri (2014) based on the wealth of Peirce's pragmatism. The Semiotic Nonagon for this research is an essential tool to reason, understand and comprehend the object of study, but also to point out, based on this reasoning, the creative process and its resulting impact.

Key Words: Semiotic nonagon, Social identity, Visual identity.

Resumo: Este artigo coloca metodologicamente a pesquisa Da identidade social à representação visual num modelo operativo de ordem qualitativo baseado na semiótica. Desenha-se, em primeiro termo, uma apropriação do modelo usado por Silva (2014) na pesquisa Imaginários urbanos em América Latina para posteriormente torná-lo mais complexo e problematizá-lo através do eneágono semiótico, modelo proposto por Claudio Guerri (2014), baseado na riqueza da pragmática de Peirce. O eneágono para esta pesquisa é uma ferramenta fundamental para razoar, entender, compreender o objeto de estudo, porém também para precisar, a partir deste razonamento, o processo criativo, seu resultado e seu impacto.

Palavras-chave: Eneágono semiótico, identidade social, identidade visual, metodologia.

\section{Introducción}

La investigación "De la identidad social a la representación visual" inició su formulación en el marco del Grupo de Investigación actualmente reconocido por Colciencias" "Estudios de la Imagen" de la Unidad Académica de Diseño Gráfico de la Facultad de Artes y Diseño de la Universidad de Bogotá Jorge Tadeo Lozano en el 2013. El proyecto se ubica en la línea de investigación Historia, sociedad y cultura, y ha vinculado profesores del área de Diseño de Identidad Visual y estudiantes del Semillero de Identidad Visual. De las tres fases que se proyectaron ya han sido aprobadas por la Dirección de Investigación, Creación y Extensión de la misma Universidad en convocatorias internas de investigación desde el 2014. El objeto de estudio es la identidad social y su posibilidad de representación simbólica como forma de recuperación identitaria y de visibilización de problemáticas de orden social y patrimonial por parte del diseñador gráfico.

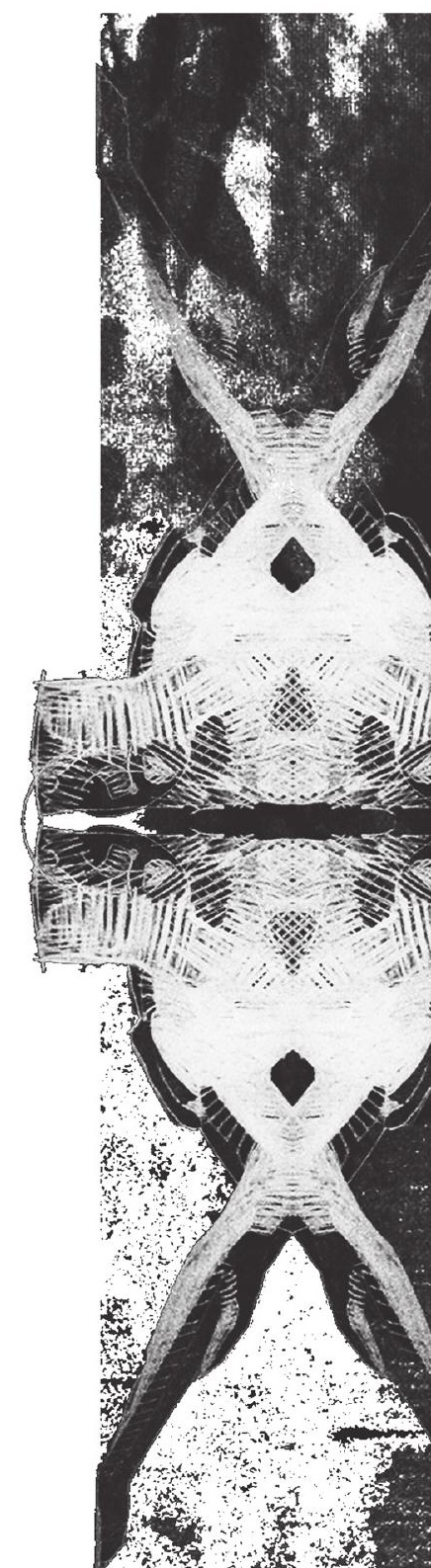


Esta representación simbólica se traduce en identificadores visuales, que con el uso serán marcas. Este campo de acción profesional del diseñador se ubica usualmente en el Branding de lugar o diseño de marcas de lugar. A pesar de que la generación de este tipo de marcas es relativamente nueva, se ha creado una necesidad en los entes de poder institucional como gobernaciones, ministerios y alcaldías, por tenerlas y cobijar bajo ellas gestiones que antes eran solo posibles bajo el dominio de delegados particulares del Estado. Para todo tipo de territorios, grandes y pequeños, países, regiones y ciudades se diseñan marcas que poseen cada vez más refinamiento en su diseño y en su posterior gestión. La formación en este tema se viene asumiendo en la mayoría de las academias como un tipo más de marca cuyo eje central es el territorio bajo la cabeza de un Estado, definido por límites que en un principio se asocia a factores turísticos, pero que en sus desarrollos posteriores amplía su cobertura a factores comerciales e incluso culturales y políticos; todo ello debido en gran parte a la creciente globalización que obliga a los diferentes territorios a vincularse a procesos macro. Las diferencias fundamentales entre la propuesta de este proyecto y la forma de asumir un proyecto de identidad de lugar de forma convencional, radica en que el protagonista no es el territorio sino los sujetos que lo habitan, estos son el centro del proyecto, pues es su identidad la que se recupera en la representación. Por otra parte, el interés no reside en el ocultamiento de sus problemáticas, sino al contrario, de la visibilización de estas como forma de autenticación de sus realidades y valoración de su identidad, lo que redunda en posibles desacuerdos con el poder de turno.

\section{La relación territorio/territorialidad/identidad}

La identidad social en construcción y transformación constante tiene como uno de sus centros de afianzamiento más importante el territorio, cuyo sentido ha ido transformándose históricamente sin llegar a omitir o eliminar por completo las interpretaciones anteriores. Por ello, reconocer el tipo de territorio al cual se ata de alguna manera la identidad de una comunidad, es de vital importancia para el diseñador, pues equivocarse en esta definición puede cambiar por completo el sentido del sistema de identidad que propondrá. De tal forma se definen de manera amplia tres posibles sentidos: 1 . Territorio interpretado en sentido tradicional como, entre otros, la necesidad de apropiación del espacio por parte de una comunidad, sus recursos naturales y su capacidad intrínseca de ser moldeado por diferentes tecnologías para proveer bienestar, esto contando con el seguimiento de leyes y normas propuestas desde el poder estatal (Ratzel). 2. Territorio definido por las relaciones que entabla en el interior y en el exterior del mismo, en donde prevalece el poder estatal, enmarcado en dinámicas globalizadoras capitalistas y caracterizado por la fluidez en la circulación de personas, objetos, productos y mercancías a todos los lugares del planeta (Gottman). 3. Territorio enmarcado en una geografía del poder, caracterizado por la existencia de múltiples poderes diferentes al del Estado que producen resistencias de diversa índole. Se le da gran importancia a la presencia de acciones y estructuras concretas y simbólicas, ganando importancia el acceso a la información que favorece procesos de territorialización (nuevos territorios), desterritorialización (destruir) y reterritorialización (construir). Desde este punto de vista la territorialidad se 
entiende como ejercicio y base de poder, y el grupo humano que asume un proceso de territorialidad puede ser desde una comunidad indígena hasta una multinacional, lo que provoca en mucho, las crisis del Estado Nación, generando diversas hibridaciones identitarias. (Raffestin, 2011; Sacks, 1997; Montañez G., 1997; Rodríguez, 2010)

En este sentido, no se pretende el diseño de identificadores de territorios enmarcados en la primera concepción, sino más bien en la segunda o la tercera, reconociendo la flexibilidad de la noción de territorio que puede ir desde el macro territorio de una comunidad (privada, pública, local, regional, nacional, internacional) hasta un microterritorio (íntimo, privado,). Esto con el fin de que las propuestas finales cumplan con el objetivo inicial de visibilización que conlleve a la recuperación de derechos de toda índole por parte de las comunidades en cuestión.

Es importante manifestar que el diseño de identificadores visuales o de sistemas dinámicos de identidad visual, y su aplicación y uso contextual posterior, no depende del diseñador, sino de los mismos miembros de la comunidad, quienes serán los veedores de su posterior gestión, por lo que los resultados podrán llegar a ser marcas convencionales, a pesar de no ser el ideal, o transformarse en símbolos visibles de apropiación y reconocimiento identitario por parte de una comunidad y de su proceso de territorialización, desterritorialización o reterritorialización.

\section{Primera Fase:}

La investigación en su primera fase se propuso un marco referencial en el que confluyeron diferentes enfoques y perspectivas alrededor de la identidad: la identidad visual, la imagen, el imaginario y el sentido; y un marco metodológico que tomó como referente los aportes de la investigación de Armando Silva sobre imaginarios urbanos, cuya base es la semiótica peirceana.

La propuesta de la primera fase fue de carácter experimental. Cada estudiante partió de un microproyecto ${ }^{4}$ que consistía en proponer una comunidad de intervención, escogida de acuerdo a unas características mínimas acordadas por el equipo. Entre estas, era indispensable que el estudiante perteneciera a la comunidad a intervenir, que reconociera una problemática social de carácter económico, cultural, racial o político que fuera evidente para la misma. Era necesario también que esta problemática tuviera suficientes referentes teóricos, simbólicos y experienciales; además el estudiante debía tener la posibilidad de realizar acercamientos etnográficos, tales como diarios de campo, entrevistas, grabaciones y lo más importante, una gran recopilación de imágenes que de acuerdo a su objetivo particular debían recoger diferentes aspectos de la comunidad en un tiempo y lugar específico, esto con el fin de lograr una mejor profundización. Con esta información primaria, y el planteamiento de los objetivos y los resultados esperados, los estudiantes debían seguir la metodología propuesta que finalizaba con el proceso creativo del diseño de un identificador o de un sistema de identidad. 
Los productos obtenidos hasta el momento en dos de los microproyectos, mostraron resultados viables y visibles, mientras que en otros dos se observaron falencias en el proceso. Estas fueron revisadas y se evidenció, en muchos casos, la falta de conocimiento por parte de los estudiantes diseñadores sobre su realidad y, por ende, incapacidad para generar posturas críticas ante la misma. Era clara la necesidad de fortalecer su formación en cultura política, definir desde qué enfoque se debía hacer y propiciar la apertura interdisciplinaria para robustecer sus posturas ante el problema que enfrentaban, de modo que se les facilitara la generación de estrategias de traducción y su posibilidad de aplicación.

Por otra parte, se encontraron debilidades en la fase inicial de formulación conceptual, lo que suscitó cuestionamientos alrededor del saber hacer alejado del saber saber: aunque la investigación referencial primaria y firmemente construida - realizada por los estudiantes con el acompañamiento del equipo- era la base para la construcción conceptual del sistema propuesto, ésta no los llevaba directamente al paso siguiente, definido en la metodología como traducción intersemiótica; en cambio, se saltaba a un proceso más práctico o al seguimiento de ciertos parámetros formales para la creación de identificadores visuales o marcas convencionales; de modo que para llegar a la creación final se dejaba de lado lo construido en las fases iniciales.

La reflexión del proceso llevado a cabo durante cerca de dos años llevó a la necesidad de profundizar en los aspectos metodológicos, complejizándolos para potenciar los resultados teóricos y prácticos derivados de la misma. Por lo tanto, se tomó la decisión de redefinir la segunda fase fortaleciendo los marcos referenciales y cuestionando la metodología. Para ello se propuso la siguiente pregunta: ¿De qué forma la semiótica pragmática aplicada como metodología permite la transformación del punto de vista convencional desde el cual se diseñan identificadores visuales de comunidades y sus territorios en el marco del sistema mundo capitalista, con el fin de propiciar posturas ideológicas, críticas y políticas que potencien el impacto de este tipo de diseño para la transformación y la visibilización social? La respuesta a esta pregunta está en proceso, y la proyección de una solución se enmarca en una transformación del enfoque inicial que se complejiza a partir de los postulados de Claudio Guerri presentados en este artículo.
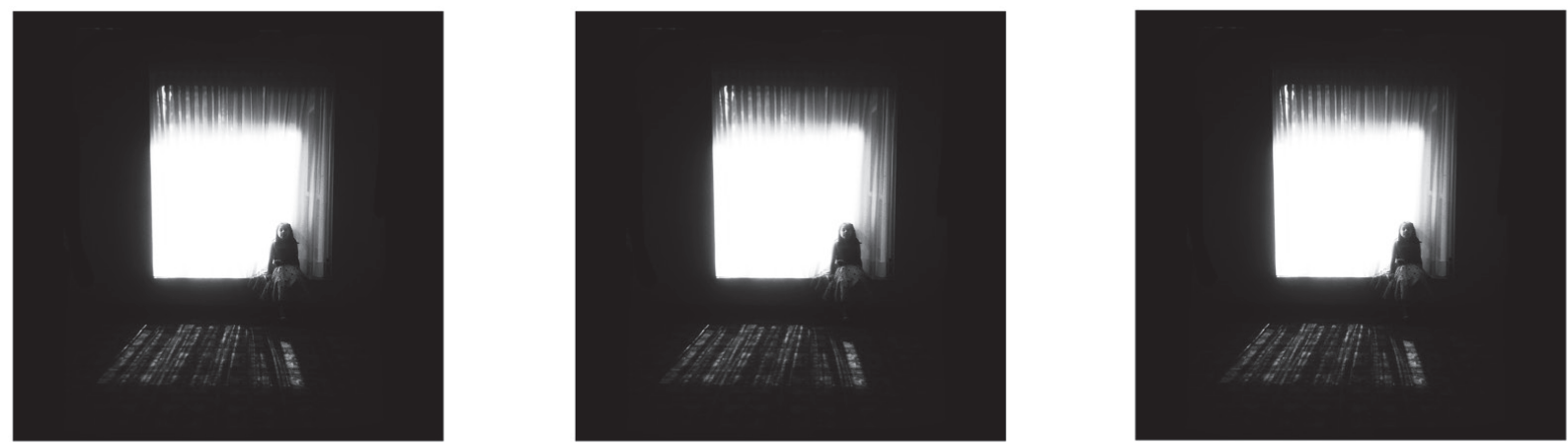
De tal forma, se explicará brevemente la metodología utilizada en la Fase 1, con base en el proyecto "Imaginarios urbanos" (Silva, 2014), para luego con más detenimiento profundizar en la problematización posterior del objeto de estudio con base en el nonágono semiótico. El resultado que se presenta en este sentido corresponde solo al primer desarrollo del signo; los subaspectos y otros signos relacionados solo serán problematizados después de la comprobación teórica del primer signo. Por otra parte, el alcance de este planteamiento solo nombra los referentes teóricos como referente contextual, pues no se constituyen en el tema central del artículo.

\section{Metodología Primera Fase}

Silva retoma las categorías peirceanas ícono, índice y símbolo para recomponer la interpretación de los imaginarios urbanos, y en su compleja lectura propone como resultado un urbanismo desde los ciudadanos que además se apoya en fuertes resultados de orden cuantitativo. Como la investigación "De la identidad social a la representación visual" parte del diseño y su enfoque es mayoritariamente cualitativo, asume los aportes de Silva en este sentido. De tal forma, a cada una de las categorías, en función de los referentes teóricos, por un lado, y por otro de la metodología proyectual propia del diseño, se le adjudicó un significado lógico que permitiera la acción de diseñar identidades visuales de territorio con un mayor grado de complejidad. De tal forma, el ordenamiento de las categorías se configuró así:

La identidad, entendida como el signo ícono, que desde la primeridad está en alguna relación o capacidad en sí mismo, y se interpreta como la comprensión de las cualidades de los actores sociales en función de sus necesidades de visibilización. Contiene la categoría estética, perceptual, sensitiva, experiencial, vivencial, etc., por lo que su herramienta base es el Atlas de Rasgos como método de investigación heurística con base en el Atlas Mnemosyne (Aby Warburg) que:

“... se nos muestra como un teatro de la memoria que sirve para mostrar significados inéditos surgidos de la conexión, a veces azarosa, de imágenes heterogéneas, al menos a primera vista. En dicho experimento intelectual el significado más que representado a través de las imágenes, surge, más bien, de la contemplación de dichas imágenes en sus conexiones más o menos fortuitas" (Martínez, F, 2010, p. 384).

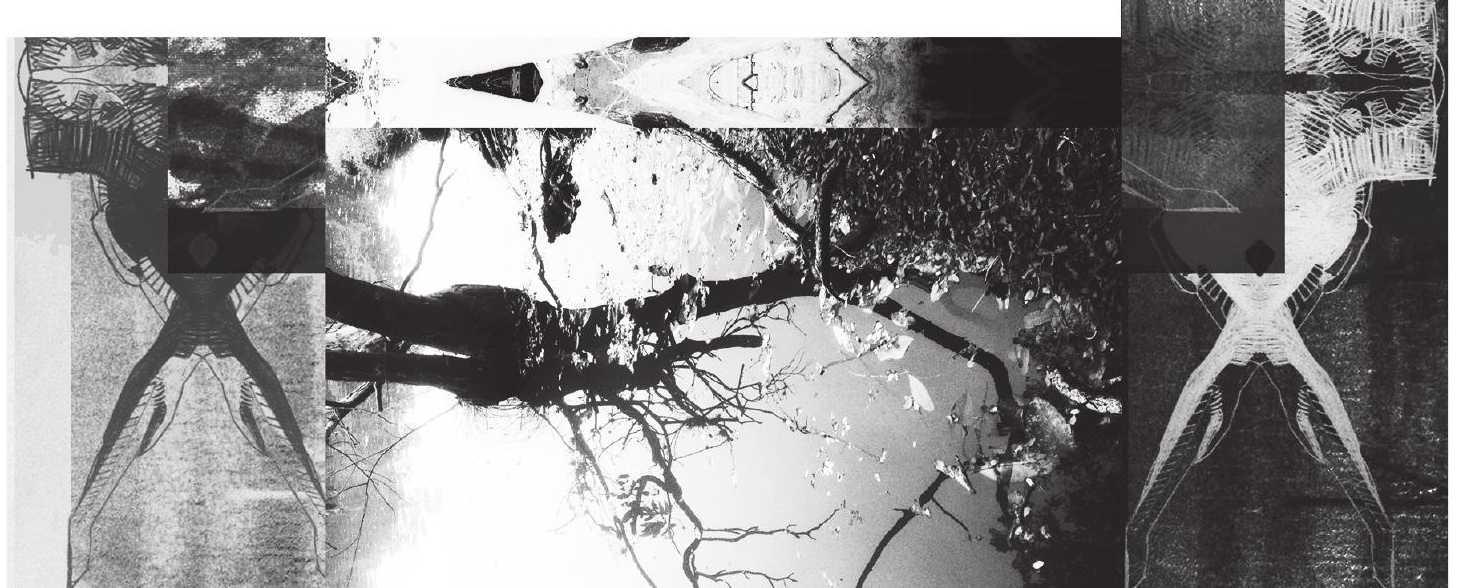


Luego, se apoya en la etnografía con historias de vida y diarios de campo, y finalmente se complementa con indagaciones de orden cuantitativo como datos estadísticos y oficiales acerca de las comunidades y su territorio dentro de diferentes parámetros que van desde la comprensión del tamaño del territorio, número de habitantes, género, raza, mortalidad, natalidad, migraciones, etc.

La traducción, comprendida como el signo índice, que desde la segundidad se manifiesta factualmente. En el diseño se refiere al enfoque relacional, en correspondencia con las acciones que debe realizar el diseñador en el proceso de llegar a un concepto e idea. Contiene las categorías "transmutación intersemiótica", "juegos de lenguaje" y "visibilidad agente". La primera (Eco) sugiere entender el mundo de contenidos y significados alrededor de una comunidad que aparece en diferentes materias: formatos, lenguajes, niveles, etc.; el diseñador, en un proceso de abstracción y síntesis, los transformará en la materia visual resultado de su trabajo creativo. La noción wittgensteniana de juegos de lenguaje, (Wittgenstein \& Rhees, 2009), se toma como referente por implicar la valoración de una serie de reglas sociales de sentido que le permiten apropiar adecuadamente la dinámica de la traducción en el juego de significación propuesto en tiempo y lugar, es decir de lo social a lo visual contextualmente; y por último, la visibilidad agente (Jacques Aumont, 1992; Alain Renaud, 1990; Didí-Huberman, 2008), pues es necesario entender la agencia de la imagen y su potencia en cuanto a los diferentes enfoques desde los que se presenta.

La mediación final, que en diseño corresponde a la creación de la imagen, es el signo símbolo, la terceridad, codificado a partir de una serie de reglas dinámicas de inclusión constante de los sujetos que habitan el territorio en representación de su identidad (J. Bourdieu, 2001; Carbó, 2002; Elgarte, 2009; Moreno T, 2008). Es el resultado final, el signo visual, el sistema y su estrategia como un producto de comunicación, que traduce una postura crítica con respecto a lo esperado de este tipo de marcas; sin dejar de lado que esto responde solamente a un punto de vista específico que por lo tanto no pretende ni generalizar, ni homogenizar la identidad, sino simplemente proponer alternativas al respecto.

Este modelo metodológico que no excluye lo proyectual, fue experimentado por los estudiantes del semillero en el desarrollo de sus microproyectos, como se explicó en la introducción de este texto.

\section{Metodología Segunda Fase}

Estas experiencias permitieron avanzar y profundizar en la propuesta metodológica, ya no para la acción sino para su validación. Por esto se adoptó el modelo propuesto por Claudio Guerri, al constituirse en una herramienta de razonamiento más complejo o, más específicamente, de producción de interrogantes que permiten orientar la investigación hacia las relaciones entre los diferentes aspectos que hacen parte del objeto que se estudia, esto es, visualizando las relaciones a través de redes conceptuales. 
Guerri $(2014)^{5}$, en su libro "Nonágono semiótico. Un modelo operativo para la investigación cualitativa” propone de manera didáctica la comprensión de la semiótica pragmática a través de un modelo operativo cuya base son los estudios y escritos de Charles Sanders Peirce, los aportes de Juan Angel Magariños de Morentin y sus propios estudios y experiencias precisamente en el campo del Diseño y la Arquitectura.

De tal forma se inició por precisar el objeto de estudio, pues habiendo avanzado en los microproyectos, se corroboraba la posibilidad del diseño de identificadoras visuales sociales para el reconocimiento y visibilidad de comunidades específicas, por lo que ese debía ser el nuevo objeto: la imagen representación de la identidad social. Se sustituyó la palabra marca para evitar su interpretación en el sentido convencional del Branding de lugar, para alejarlo de cualquier contexto comercial; se propuso en cambio un signo o señal visual solo como distinción e identificación. Se reconoce que esta imagen social no es en su origen representación sino sustitución-figuración e incluso solo presentación, aludiendo esta última a las interpretaciones que desde el giro icónico pueden o se están haciendo de ella, aunque en su uso se interprete como representación a causa de los parámetros clasificatorios en los que es inscrita por sus usuarios y desafortunadamente donde queda retenida, apreciada y analizada.

“(...) la imagen que no pretende representar; que se opone incluso a la idea de presentación de aspectos conocidos de la realidad (...). Sin embargo, en la cuasi-totalidad del conjunto de imágenes ordinarias, se trata, a través del espacio o a través del tiempo, de recrear visualmente una porción del universo para encerrarla ante mis ojos, al interior de mi esfera personal. Se trata efectivamente de la experiencia vicaria, y es también, guía para un análisis lógico de la génesis de la imagen que -sin demasiados escrúpulos históricos- retoma, a instancia de Condillac, la recreación imaginaria de lo real, la idea de un "figurativismo" subyacente en la conciencia occidental"(Moles, 1991, p. 27)

Interpretar esta imagen en este sentido, solo será posible en el proceso mismo de diseño, pues en el proceso de inserción social esta resemantización será apropiada por la comunidad pragmática que la asimilará. Su comprensión podrá ser la esperada en un sentido positivo o correrá el riesgo de tener un significado implícito, siempre al servicio de la sociedad capitalista, con una función comunicativa importante acorde con las prácticas de consumo, de las formas actuales de manipulación y de la superposición de los sistemas de poder dominantes; en este sentido es deudora al igual que el infodesign, como lo referencia Ledesma (2010), "del predominio alcanzado por la información, la comunicación y el conocimiento en la etapa del capitalismo cognitivo "inscripto, a su vez, en una transformación de los discursos sociales que celebran la inmediatez, la velocidad, la amigabilidad y accesibilidad", contrario a los postulados originales del "giro icónico" (p. 5).

La identidad social como concepto, es definida grosso modo como las afinidades compartidas por un colectivo de individuos que se manifiestan en ciertas prácticas culturales, sociales, económicas, etc. en un espacio con límites de algún tipo, categoría que se complejiza por estar compuesta por la noción de identidad y de territorio/ 
territorialidad. La primera, alimentada por estudios psicológicos y antropológicos desde autores como De la Torre Molina (2007), Giménez C. (2005), Restrepo (2009) y Sen A. (2000); y la segunda, que define las relaciones entre territorio y territorialidad está siendo estudiadas a partir de autores como Ratzel (1987), Raffestin (2011), Sacks (1983), Beck (1999), Canclini (2000), Sassen (2001), entre otros, como se explicó en la introducción de este artículo.

La aplicación del nonágono permitirá responder a la postura ideológica y política desde la cual es posible darle otro sentido al objeto que se configura y amplía en esta relación y que como se dijo anteriormente se denomina, "Imagen representación de

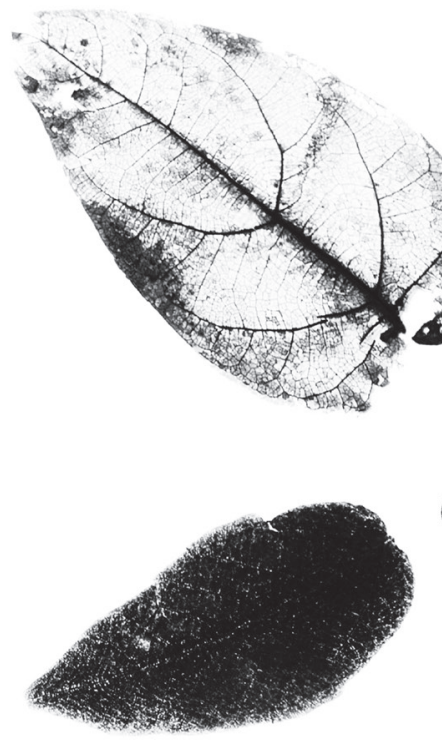
identidad social”.

El nonágono como encuadre lógico semiótico de orientación peirceana exige el planteamiento del objeto desde una comprensión triádica, lo que admitirá más adelante que cada uno de estos tres signos pueda volver a ser pensado en sub-aspectos en esa misma dimensión triádica y así sucesivamente, confirmando la posibilidad de la significación infinita.

El planteamiento de orden conceptual del nonágono semiótico implica el reconocimiento de aspectos operativos y de aspectos descriptivos. Los primeros corresponden a los correlatos y los segundos a las tricotomías. Los correlatos entonces, corresponden a la primera partición del signo, que según Guerri (2014), "pueden caracterizarse como categorías materiales u operativas y aluden a los modos de manifestarse o de ser que tiene el signo"(p.10).

Para definir los correlatos del signo Imagen representación de la identidad social, se profundizó en la creación, la gestión y el alcance de la imagen de la identidad visual: símbolos, logotipos, imagotipos, isotipos, etc.; y sobre esta comprensión se problematizó en sus subaspectos, motivados por las preguntas iniciales de la investigación que buscaban cuestionar al diseño gráfico sobre el impacto social de los resultados de su acción profesional en un contexto contemporáneo, en el cual este tipo de identidad visual es tendencia. De tal forma se identificaron como correlatos los siguientes:

\begin{tabular}{|c|c|}
\hline Primer correlato - Forma & La identidad visual como forma estética convencional de carácter retórico. \\
\hline Segundo Correlato - Existencia & La identidad visual, como acción manifiesta productora de sentido. \\
\hline Tercer Correlato - Valor & La identidad visual, como empoderamiento y potencia para la transformación social. \\
\hline
\end{tabular}

Cuadro No. 1. Correlatos del nonágono de la imagen representación de identidad social 


\begin{tabular}{|c|c|}
\hline Primera Tricotomía - Forma & Predicado de la idea de la imagen de la identidad visual como posibilidad. \\
\hline Segunda Tricotomía - Existencia & Modos concretos de aparecer de la identidad visual. \\
\hline Tercera Tricotomía - Valor & Forma y reglas de la mediación para la representación y su interpretación. \\
\hline
\end{tabular}

Cuadro No. 2. Tricotomías del nonágono de la imagen representación de identidad social

Los aspectos descriptivos, las tricotomías, corresponden a la segunda partición del signo o ampliación triádica de cada uno de los aspectos de los correlatos, lo que supone la identificación de la primeridad, segundidad y terceridad para cada uno de ellos y que retomando a Guerri se constituyen en categorías teórico conceptuales o modo conceptual en el que se entiende el signo. ${ }^{6}$ La determinación de las tricotomías define las relaciones que aclaran el objetivo de la imagen representación de identidad social desde su percepción, interpretación, interiorización, asimilación y aceptación como representación identitaria.

La primera tricotomía, se ubica en la primeridad y predica las cualidades y valores intrínsecos de la identidad visual desde sus aspectos formales y conceptuales, determinando metafóricamente características propias de este tipo de signo a todo nivel, que pueden ser percibidas como tales, siempre como posibilidad.

La segunda corresponde a la segundidad y marca una relación referencial con respecto al primer signo a través de las estructuras, las tipologías y las relaciones contextuales visuales, esto hace que el signo exista e indique la identidad que representa a través de unas dinámicas de inserción y un lenguaje específico.

La tercera triada corresponde a la terceridad por determinar y reglamentar el sistema de identidad y la forma en como deberá ser implementado para su adecuada interpretación. Esto es la estrategia desde la cual inicia su gestión, que parte de criterios estéticos, económicos y políticos de forma similar a cualquier otro signo inscrito pragmáticamente en la cultura con el mismo fin o con otros fines.

La relación entre los correlatos y las tricotomías da inicio al planteamiento del nonágono ${ }^{7}$ semiótico como opción de cambio del tradicional punto de vista de la gestión de los identificadores de orden social.

El diagrama da cuenta de los tres aspectos de la constitución de la imagen representación de identidad social a considerar tanto para el análisis de signos ya existentes o para el diseño de nuevos signos dentro de este campo. 


\begin{tabular}{|c|c|c|c|}
\hline $\begin{array}{r}\text { NONÁGONO SEMIÓTICO } \\
\text { IMAGEN } \\
\text { REPRESENTACIÓN DE } \\
\text { IDENTIDAD SOCIAL }\end{array}$ & $\begin{array}{l}\text { Predicado de la idea de la } \\
\text { imagen de la identidad visual } \\
\text { como posibilidad. }\end{array}$ & $\begin{array}{l}\text { Modos concretos de } \\
\text { aparecer de la identidad } \\
\text { visual. }\end{array}$ & $\begin{array}{l}\text { Forma y reglas de } \\
\text { la mediación para la } \\
\text { representación y su } \\
\text { interpretación. } \\
\text { Tercera Tricotomía - Valor }\end{array}$ \\
\hline $\begin{array}{l}\text { La identidad visual } \\
\text { como forma estética } \\
\text { convencional de carácter } \\
\text { retórico. }\end{array}$ & $\begin{array}{l}\text { FF } \begin{array}{l}\text { Forma de la Forma } \\
\text { (Cualisigno) }\end{array} \\
\\
\text { - } \quad \text { Atlas de ragos. } \\
\text { - Imaginarios. } \\
\text { - Estéticas particulares. } \\
\text { - Imagen como posibilidad } \\
\text { de representación. }\end{array}$ & $\begin{array}{l}\text { EF Existencia de la Forma } \\
\text { (Sinsigno) } \\
\\
\text { - Traducción intersemiótica } \\
\text { - Juegos de lenguaje } \\
\text { - Elementos básicos del dise- } \\
\text { ño: Color, tipografía, forma, } \\
\text { textura. }\end{array}$ & $\begin{array}{l}\text { VF Valor de la Forma } \\
\text { (Legisigno) } \\
\text { Dispositivo sentimiento } \\
\text { sensibilización } \\
\text { - Valor estético de la identi- } \\
\text { dad visual. } \\
\text { - Valor de la imagen articula- } \\
\text { da. } \\
\text { - Valor de la identidad social. }\end{array}$ \\
\hline $\begin{array}{l}\text { La identidad visual, } \\
\text { como acción manifiesta } \\
\text { productora de sentido. }\end{array}$ & $\begin{array}{l}\text { FE Forma de la Existencia } \\
\text { (Icono) } \\
\text { - Valor social de la comuni- } \\
\text { dad. } \\
\text { - Referentes socioeconómi- } \\
\text { cos, políticos, culturales. } \\
\text { - Problemas sociales. }\end{array}$ & $\begin{array}{l}\text { EE } \begin{array}{l}\text { Existencia de la Existencia } \\
\text { (Indice) }\end{array} \\
\text { - Signo identificador visual } \\
\text { - Tipología y sistema. } \\
\text { - Comunicación gráfica } \\
\text { impresa y audiovisual } \\
\text { representativa para cada } \\
\text { comunidad NO relaciona- } \\
\text { das con merchandising. }\end{array}$ & $\begin{array}{l}\text { VE Valor de la Existencia } \\
\text { (Símbolo) } \\
\text { Dispositivo conocimiento } \\
\text { reconocimiento } \\
\text { - Validez de la representa- } \\
\text { ción gracias a su estrategia } \\
\text { de comunicación y circula- } \\
\text { ción y al tipo de penetra- } \\
\text { ción social. } \\
\text { - Relevancia del sistema } \\
\text { gráfico y audiovisual. }\end{array}$ \\
\hline $\begin{array}{l}\text { La identidad visual, } \\
\text { como empoderamiento } \\
\text { y potencia para la } \\
\text { transformación social. }\end{array}$ & $\begin{array}{l}\text { FV } \begin{array}{l}\text { Forma del Valor } \\
\text { (Rhema) }\end{array} \\
\\
\text { - } \quad \text { Desigualdad social. } \\
\text { - Inequidad. } \\
\text { - Invisibilización de algunos } \\
\text { actores sociales. } \\
\text { - Falta de cobertura de } \\
\text { - Políticas públicas. } \\
\text { - Pérdida del patrimonio }\end{array}$ & $\begin{array}{l}\text { EV Existencia del Valor } \\
\text { (Dicisigno) } \\
\text { - } \begin{array}{l}\text { Necesidad de reconoci- } \\
\text { miento. }\end{array} \\
\text { - Cambio en la percepción } \\
\text { social. } \\
\text { - Protagonismo en la toma } \\
\text { de desiciones que los afec- } \\
\text { tan. }\end{array}$ & $\begin{array}{l}\text { VV Valor del Valor } \\
\text { (Argumento) } \\
\text { Marca Dispositivo poder } \\
\text { empoderamiento } \\
\text { - Apropiación por identifica- } \\
\text { ción y afirmación propia. } \\
\text { Visibilización o reconoci- } \\
\text { miento social . } \\
\text { - Asombro, temor, respeto, } \\
\text { valoración y ejecución de } \\
\text { acciones de mejora. }\end{array}$ \\
\hline
\end{tabular}

Cuadro No. 3. Nonágono de la imagen representación de identidad social

De acuerdo a los correlatos:

1. Concepto y forma. Definición de tipología y el estilo, entre otros, como proyección de identidad.

2. El emplazamiento del identificador dentro de un sistema con relación a las necesidades de una comunidad identificada y de su territorio, sea este físico, virtual o simbólico.

3. El posicionamiento del identificador a través de la estrategia de comunicación y penetración como mediatización.

De acuerdo a las tricotomías:

1. La percepción sensible de la imagen como posibilidad de identificación.

2. La dimensión política de la imagen a través de sus modos de ser.

3. La confirmación de la validez de la imagen representación de identidad social en su uso y en su apropiación, gracias a la eficacia de su gestión y de su estrategia de imposición. 
Esta imposición no se refiere a un tipo de violencia, pues este tipo de signos ha llevado un proceso en el cual sutilmente se ha insertado positiva o negativamente en el contexto, según Bourdieu (2006) gracias a que los criterios definitorios de la identidad corresponden a:

"actos de percepción y de apreciación, de conocimiento y de reconocimiento, donde los agentes envisten sus intereses y sus presupuestos, y de representaciones objetales, en cosas (emblemas, banderas, insignias, etc.) o actos, estrategias interesadas de manipulación simbólica, que pretenden determinar la representación (mental), que los otros pueden hacerse de estas propiedades y de sus portadores". Que sugieren luchas constantes a propósito de las identidades "luchas de las clasificaciones, luchas por el monopolio del poder de hacer ver y de hacer creer, de hacer conocer y de hacer reconocer, de imponer la definición legítima de las divisiones del mundo social, y por ello, de hacer y de deshacer los grupos: estas luchas tienen en efecto por apuesta el poder de imponer una visión del mundo social a través de los principios de división que, cuando se imponen al conjunto de un grupo, hacen el sentido y el consenso sobre el sentido, y en particular sobre la identidad y la unidad del grupo" (p.169-170).

Hasta este punto es posible reconocer complejidades en el diseño de este tipo de símbolos, pues suponen considerar las diferentes necesidades del territorio y de los individuos que lo habitan o lo re - simbolizan además de los diferentes intereses que subyacen al mismo, y no solo lo limitado por el encargo cuyo objetivo final puede encontrarse en el plano comercial en pro de potenciar y fomentar el turismo, el comercio, o la diversidad cultural y cuyo trasfondo puede ser y por lo general lo es, más económico que turístico.

Revisando conceptualmente cada una de las triadas que se han formado en el nonágono, se puede decir que la primera tricotomía, el signo en relación consigo mismo, no excluye al sujeto interpretante, pero la interpretación se sucede antes de su actualización en alguna de sus manifestaciones. Este signo reúne como posibilidad todos los conocimientos alrededor del diseño de identidad visual, las teorías de diseño, incluso el branding, las metodologías, sus posibilidades de interrelación con la publicidad y el mercadeo o con la sociología u otras humanidades. No obstante, sólo una o algunas de ellas se manifestarán concretamente en su actualización en la segunda tricotomía, esto es, con las cargas simbólicas que se hayan fijado de acuerdo a los contenidos conceptuales e ideológicos desde los cuales haya sido determinada su manifestación.

La segunda tricotomía reúne las manifestaciones concretas, existenciales del signo identidad visual que se van complejizando en la medida en que entablan relaciones materiales con otros signos. Es el signo en relación con su objeto. En este sentido se aprecia el sistema. Las piezas informativas, la armonía general del mismo, el tono del discurso, etc. La estabilidad del sistema mantiene una relación de armonía con el sujeto que lo percibe, siendo protagónico el sistema más que el sujeto, por lo que se mantiene una relación de inercia que inicia el proceso de reconocimiento. 
Y la tercera tricotomía alude a la relación del signo con su interpretante, a la valoración estratégica de las manifestaciones existenciales presentes en la segunda tricotomía. Se reúnen aquí todas las terceridades de los correlatos por lo que se explicará desde los dispositivos sensibilidad, conocimiento y poder en relación directa a Foucault y sus postulados sobre el concepto, entendiéndolo siempre en su dimensión estratégica dominante (Agamben, 2011). En la primeridad, a través de la sensibilidad, se llega a las posibilidades de la experiencia como tal, desde el punto de vista fenomenológico, experiencia que podrá ser de carácter estético, histórico o filosófico; según Gadamer, citado por Canán, A., 2002, es una experiencia sui generis, inalcanzable para la razón, es decir “...) toda aquella experiencia que no puede ser verificada por la ciencia"(...)" (Gadamer, 1993, p.166).

En la segundidad, el conocer implicaría detenimiento sobre la imagen que prioriza los aspectos formales y cuantificables; su ubicación en un plano simbólico reconocido, es el paso del saber al conocer, en el cual hay comprensión de dimensiones y alcances de la imagen.

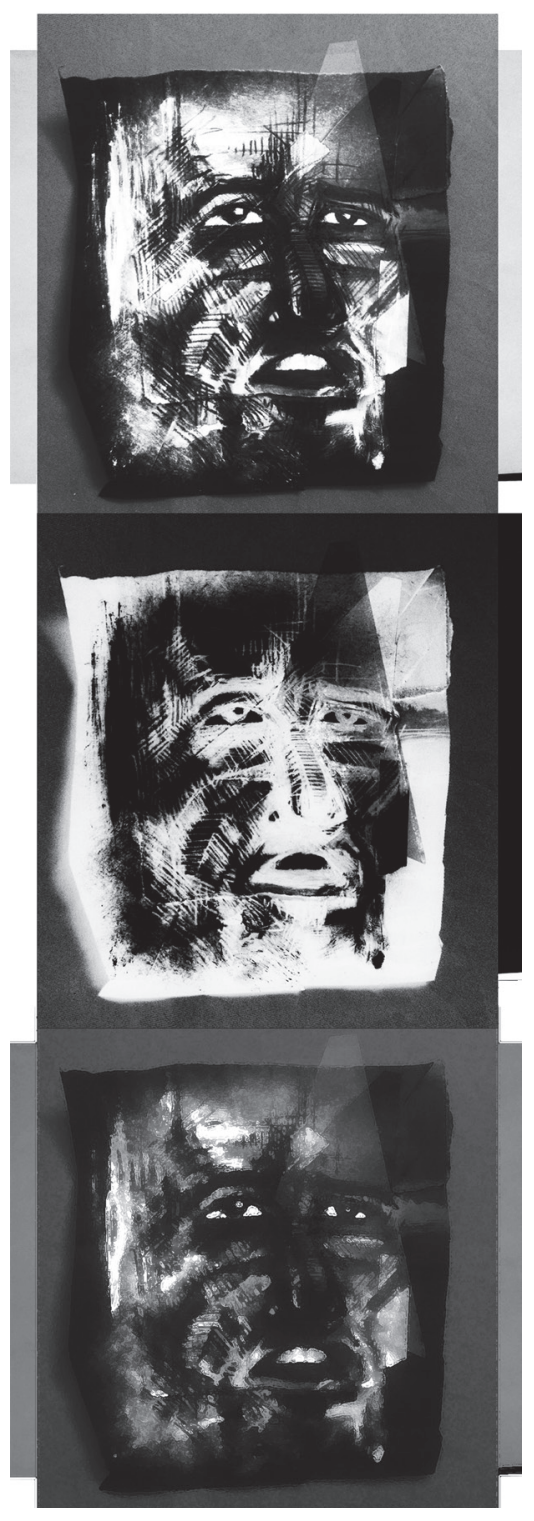

En la terceridad, se da el proceso final de empoderamiento, reconocimiento y búsqueda. No es posible desconocer que la transmisión de los identificadores visuales obedece a las dinámicas de los mass media y los transmedia, ante los cuales una gran mayoría de espectadores sufre de analfabetismo mediático; ésta es una de las mayores razones por las cuales se constituyen en el medio por excelencia para la vigilancia y el control y para la transmisión de ideologías dominantes, lo que resulta en la eficacia de la inserción de este tipo de símbolos en cualquier sociedad. Sin embargo, desde el punto de vista crítico, si el sujeto ha sido integrado al proceso, es posible que forje una postura crítica ante el mismo.

En ninguno de estos tres momentos se excluyen los demás, pues el signo es indivisible. Por ejemplo, en la primeridad, en la misma alusión al hecho sensible que se presenta como dominante, se expresa de forma relegada la comprensión y el juicio del sujeto y se produce tanto la fijación, a través de la pregnancia de la forma, como la formación de un juicio. En esta medida, el sujeto ante la imagen podría pasar de una visión desprevenida a una observación crítica en cualquier momento y actuar en consecuencia. De tal forma el sujeto puede sentirse atraído por la marca, su color, su forma, su vocatividad y su pregnancia, detenerse para reconocer el contexto en el cual se presenta y finalmente asumir una postura crítica o no ante la invitación que esta imagen articulada le hace. 


\section{Comentarios finales}

- A partir de la organización del signo identidad social y sus relaciones en el nonágono, es posible continuar con el siguiente paso propuesto por Magariños de Morentín (2008), que establece la agrupación de los diferentes signos para determinar semióticas particulares, gradualizar la clasificación y anticipar recorridos visibles que potenciarán los resultados.

- La primera fase de la investigación puede ser problematizada en uno de los subaspectos del nonágono semiótico que se ha construido. Sin haber iniciado el análisis de algún subaspecto aún, es posible atreverse a iniciar con la forma de la forma para profundizar en este tipo de imagen en particular.

- El nonágono semiótico como modelo supone la complejización del objeto de estudio desde diferentes perspectivas enriqueciendo, definitivamente, las posturas desde las cuales se asume cualquier investigación.

- El nonágono semiótico, al mismo tiempo que potencia posibilidades dentro de la investigación que permiten su expansión, trasluce posibles vacíos o quiebres en las categorías teórico-conceptuales y en las relaciones en las mismas, exigiendo mayores niveles de profundización, precisión en la delimitación y la claridad en la determinación del enfoque político que precise la incidencia de la investigación en diferentes planos y enfoques tanto en el entorno social, en el entorno cultural, en las instituciones como en la perspectiva humana.

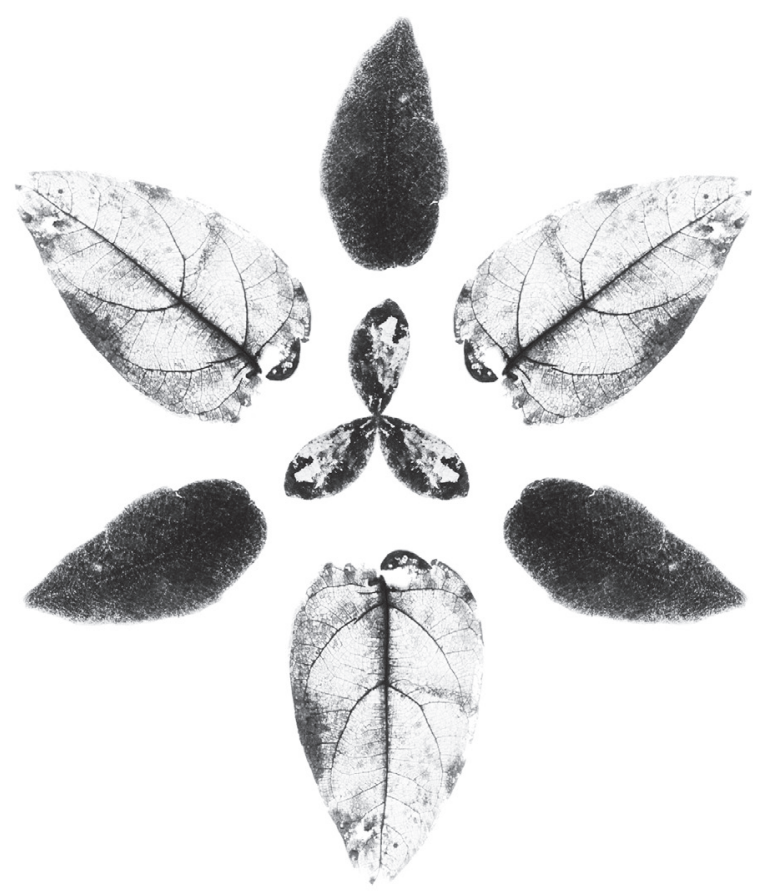




\section{Notas}

${ }^{1}$ Artículo con base en la ponencia presentada en el XI Congreso Diseño en Sociedad. Universidad del Valle.

${ }^{2}$ Formación de Pregrado: Diseño Gráfico, Universidad Nacional de Colombia; Posgrados: Especialización en Pedagogía de la Comunicación y Medios interactivos y Maestría en Comunicación Educación de la Universidad Distrital Francisco José de Caldas; estudiante del Doctorado en Estudios Sociales en la Universidad Externado de Colombia. Docente Asociado II en la Universidad de Bogotá Jorge Tadeo Lozano, miembro del Grupo de Investigación en Estudios de la Imagen de la misma universidad.

${ }^{3}$ Departamento Administrativo de Ciencia, Tecnología e Innovación (Colombia)

${ }^{4}$ Proyectos adelantados hasta el momento: "El Aguante" y "San Victorino", ambos del estudiante Steven Porras; "Identidad cultural-Casanare", de la estudiante Oriana Danitza García y "Píntela”, del estudiante Sebastián Márquez.

${ }^{5}$ Claudio Guerri. Arquitecto profesional, docente especialista en Semiótica aplicada, con 42 años de trayectoria. Trabaja en CfG y Asociados - Investigación Semiótica. Ejerce la docencia en Carrera de Arquitectura FADU-UBA.

${ }^{6}$ Siguiendo a Guerri (2014, p. 12), se referenciarán los signos originales de Peirce (CP 2.243 y ss) pero con la denominación propuesta por Magariños de Morentín (1983:91; 1984:195), por lo que la primeridad recibe el nombre de forma, la segundidad, se denomina existencia y la terceridad, valor y en relación tanto a los correlatos como a la tricotomía y en el mismo orden, reciben el nombre de posibilidad, actualización y necesidad o ley. En la ubicación en el nonágono, en la primera tricotomía, reciben los nombres: (cualisigno)forma de la forma, (sinsigno)forma de la existencia, (Legisigno)forma del valor; en la segunda tricotomía, (ícono) existencia de la forma, (índice) existencia de la existencia y (símbolo) existencia del valor; y en la tercera tricotomía, (Rhema) valor de la forma, (Dicisigno) valor de la existencia y (Argumento) valor del valor.

${ }^{7}$ La construcción de este nonágona toma como referentes los ejemplos que Claudio Guerri ofrece muy didácticamente en su libro y fundamentalmente el nonágono del signo Arquitectura, con el cual determina las 10 clases de signos de la habitabilidad (p. 27).
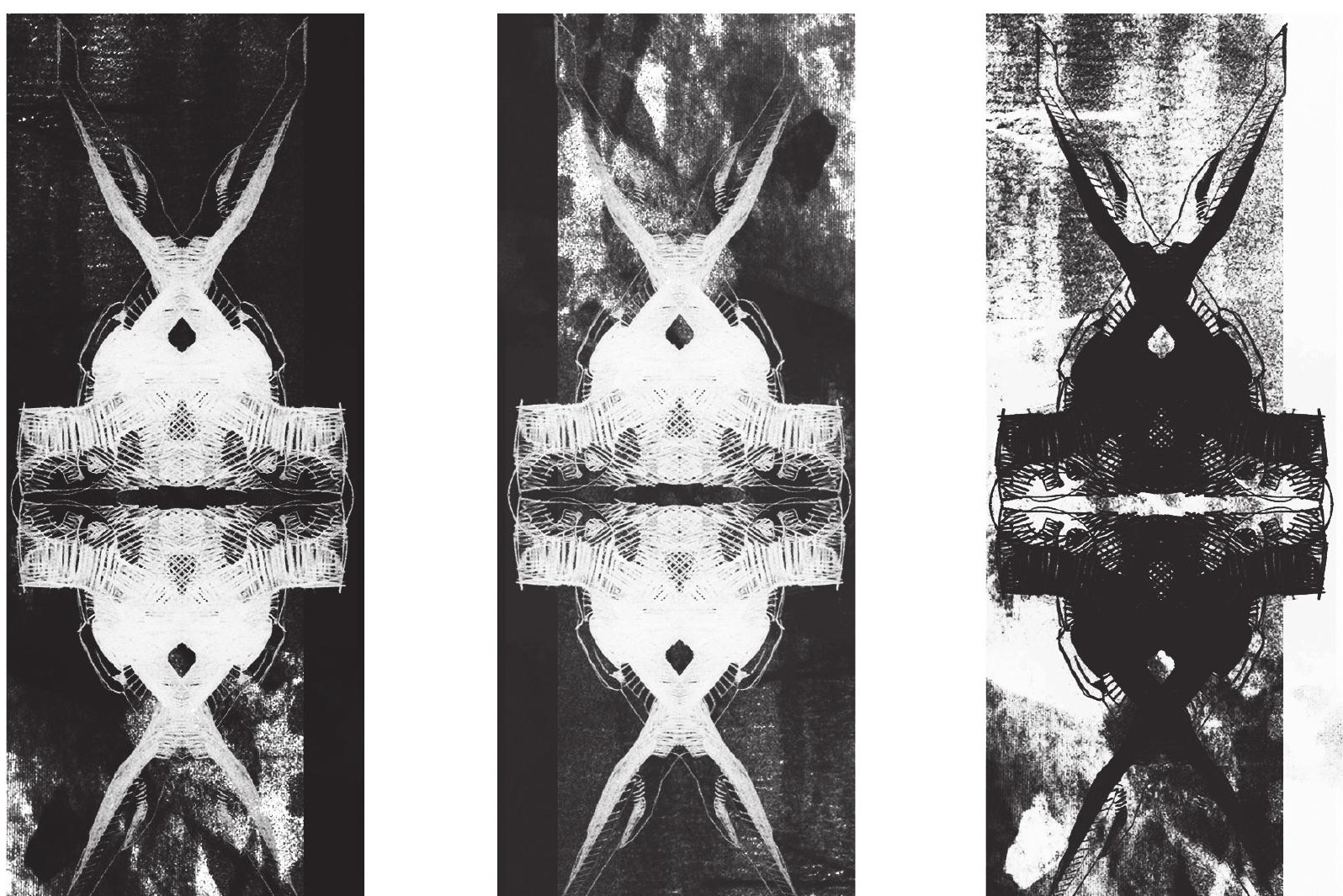
